\title{
DIVERGÊNCIA ENTRE CULTIVARES DE MILHO TRANSGÊNICO E NÃO TRANSGÊNICO SOB CULTIVO NO CERRADO
}

Divergence between transgenic and non-transgenic corn cultivars cultivated in the Cerrado

Divergencia entre cultivares de maíz transgénicos y no transgénicos en cultivo en el Cerrado

\author{
Márcio Eckardt* ${ }^{*}$, Ila Raquel Mello de Cardoso ${ }^{1}$, Núbia Adriane da Silva ${ }^{2}$, Flávio Sérgio \\ Afférri $^{3}$, Joenes Mucci Peluzio ${ }^{4}$ \\ ${ }^{1}$ Doutorando em Biodiversidade e biotecnologia, Rede BIONORTE, Palmas, Brasil. \\ ${ }^{2}$ Instituto Federal de Educação Ciência e Tecnologia do Tocantins, Paraiso do Tocantins, Brasil. \\ ${ }^{3}$ Centro de Ciências da Natureza, Universidade Federal de São Carlos, São Carlos, Brasil. \\ ${ }^{4}$ Laboratório de Pesquisas agropecuárias, Universidade Federal do Tocantins, Palmas, Brasil.
}

*Correspondência: Instituto Federal de Educação, Ciência e Tecnologia do Tocantins, Parque Agroindustrial, BR 153, Km 480, Paraíso do Tocantins, Tocantins, Brasil.CEP:77.600-000 e-mail adm1marcio@ifto.edu.br

Artigo recebido em 19/02/2021 aprovado em 05/07/2021 publicado em 26/10/2021

\section{RESUMO}

$\mathrm{O}$ crescente uso da transgenia em programas de melhoramento pode levar a efeitos adversos na cultura do milho. O estudo comparativo entre cultivares transgênicas e não transgênicas disponíveis no mercado, sob diferentes doses de nitrogênio, no cerrado tocantinense, teve o objetivo de identificar os efeitos das tecnologias na diversidade genética. Foram realizados dois ensaios em Paraíso do Tocantins e dois em Palmas, com semeaduras em novembro de 2018 e janeiro de 2019. O delineamento experimental foi de blocos ao acaso, com três repetições. Em cada ensaio, foi realizada adubação de cobertura com 50,100 e $150 \mathrm{~kg}$ de N (Nitrogênio) por ha ${ }^{-1}$. Para cada dose de N, e para análise conjunta, foram obtidas a contribuição relativa das características, medidas de dissimilaridade e a formação de grupos. Para a análise conjunta, foi realizado o método hierárquico da distância média. Em sua maioria, a composição dos grupos similares formados foi constituída tanto pelas cultivares transgênicas quanto pelas não transgênicas. A adubação de $100 \mathrm{~kg}$ de $\mathrm{N}$ por ha-1 ${ }^{-1}$ proporcionou o maior número de grupos, indicando que pode ser utilizada para estudos futuros para distinção de genótipos. As características que mais contribuíram relativamente para a dissimilaridade foram o número de grãos por fileira (NGF) e o comprimento da espiga com palha (CECP).

Palavras-chave: biotecnologia; dissimilaridade; tecnologia de semente.

\section{ABSTRACT}

The growing use of transgenics in breeding programs can lead to adverse effects on corn crop. The comparative study between transgenic and non-transgenic cultivars in the Cerrado biome of Tocantins/Brazil available in the market, in different nitrogen doses, sought to identify the effects of technologies on genetic diversity. Two trials were conducted in the municipality of Paraíso do Tocantins, and two trials were conducted in Palmas city, with sowing dates in November 2018 and January 2019. The experimental design was randomized blocks with three replications. In each trial, top-dressing fertilization was performed with 50, 100, and $150 \mathrm{~kg}$ of $\mathrm{N}$ (Nitrogen) per ha-1. For each dose of $N$, and for joint analysis, the relative contribution of characteristics, dissimilarity measurements, and group formation were obtained. For the joint analysis, the hierarchical method of mean distance was used. In addition, the 
joint analysis was submitted to a hierarchical average distance method. The composition of similar groups was mostly formed by transgenic and non-transgenic cultivars. Fertilizing $100 \mathrm{~kg}$ of $\mathrm{N}$ per ha-1 has provided the largest number of groups, indicating that it can be used for future studies to distinguish genotypes. The characteristics that most contributed relatively to the dissimilarity were the number of grains per row and the length of the corn cob.

Keywords: biotechnology; dissimilarity; seed technology.

\section{RESUMEN}

El creciente uso de transgénicos en programas de mejoría puede llevar a efectos adversos en el cultivo de maíz. El estudio comparativo entre cultivares transgénicos y no transgénicos disponibles en el mercado, bajo distintas dosis de nitrógeno, en el Cerrado de Tocantins, tuvo el objetivo de identificar los efectos de las tecnologías en la diversidad genética. Han sido realizados dos ensayos en la ciudad de Paraíso de Tocantins y dos en la ciudad de Palmas, con siembra en noviembre de 2018 y enero de 2019. El trazado experimental fue de bloques al azar con tres repeticiones. En cada ensayo fue realizada fertilización de cobertura con 50, 100 y $150 \mathrm{~kg}$ de N (nitrógeno) por ha-1. Para cada dosis de $N$, y para análisis conjunta, fueron obtenidas la contribución relativa de las características, medidas de desemejanza y la formación de grupos. Para el análisis conjunto se utilizó el método jerárquico de distancia media Además, el análisis conjunto ha sido sometido al método jerárquico de distancia media. En su mayoría, la composición de los grupos similares formados ha sido constituida no solo por los cultivos transgénicos, sino también por los no transgénicos. La fertilización de $100 \mathrm{~kg}$ de $\mathrm{N}$ por ha-1 ha proporcionado el mayor número de grupos, lo que indica que se puede utilizar para estudios futuros para distinguir genotipos. Las características que más contribuyeron relativamente para la disimilitud fueron el número de granos por hileras y la longitud de mazorca con paja.

Descriptores: biotecnología; disimilitud; tecnología de semilla.

\section{INTRODUÇÃO}

A cultura do milho (Zea mays L.), fonte alimento para seres humanos e animais, com importância social e econômica, é considerada como um dos pilares do sistema produtivo agropecuário brasileiro (FILHO E BORGHI, 2018).

Segundo Artuzo et al. (2019), o caminho da importância da cultura é trilhado por meio dos ganhos constantes de produtividade que tem relação direta com o desenvolvimento de novas cultivares mais produtivas, adaptadas a diferentes climas, resistentes a pragas e que respondem com maior positividade ao uso de técnicas modernas de produção.

Dentre as técnicas modernas de produção, o uso do Nitrogênio $(\mathrm{N})$ e a diversidade genética têm sido frequentemente estudadas por pesquisadores como Santos et al. (2014), Carvalho et al. (2016), Afférri et al. (2020) com o objetivo de identificar cultivares com possibilidades de adaptação em diferentes ambientes de cultivo e regiões produtoras.
$\mathrm{Na}$ busca pelo entendimento do 88 comportamento da cultura em diferentes ambientes de cultivo, estudos de Sodré et al. (2016), Nardino et al. (2017), Santos et al. (2018), Afférri et al. (2020) buscaram investigar as características que podem ser importantes para a seleção de materiais promissores em produtividade e diversidade da cultura que anualmente é disponibilizada aos produtores em maior número de cultivares transgênicas.

Entretanto, o desenvolvimento de novas cultivares para um determinado ambiente está atrelado ao uso do melhoramento genético, que vem causando controvérsias quanto a possíveis riscos à saúde e ao meio ambiente, o que vem acalorando debates na comunidade científica (COSTA, 2013, ULTCHAK, 2018).

Diniz (2011) afirma que a inserção de um genoma de interesse no genoma de outra espécie pode interferir na morfologia da planta receptora, assim como na sua estabilidade. 
Além disso, Costa (2013) e Burg (2017), em estudo sobre a diversidade genética de cultivares de milho no estado de Santa Catarina, verificaram que os recursos genéticos vegetais podem estar sofrendo erosão genética, levando a impactos na conservação da diversidade de recursos, devido ao modelo de agricultura que vem sendo desenvolvido nas últimas décadas.

Ramos et al. (2020) apontam que híbridos portadores de genes de interesse poderão ser utilizados como material comercial, desde que apresentem fortes atributos tecnológicos e níveis de produtividade igual ou superior aos já existentes no mercado. Apontam, ainda, que a estratificação de melhoramentos concentrados em cultivares "elite", pode levar a redução no número de materiais com maior rusticidade e prejudicar futuros cruzamentos.

Nesse sentido, foi realizado estudo com o objetivo de identificar a divergência entre cultivares transgênicas e não transgênicas disponíveis no mercado local, inicialmente através de medidas de dissimilaridade, e, posteriormente, foi realizado o agrupamento das mesmas. Além disso, foram identificadas as características que mais contribuíram para a divergência genética das cultivares de milho sob cultivo no cerrado.

\section{MATERIAIS E MÉTODOS}

Foram realizados quatro ensaios de cultivares de milho no estado do Tocantins, no norte brasileiro, sendo dois realizados em Paraíso do Tocantins $\left(10^{\circ} 26\right.$ Sul; longitude: $48^{\circ} 88$ Oeste e altitude: $411 \mathrm{~m}$ ) e dois em Palmas (latitude: $10^{\circ} 45 \mathrm{Sul}$; longitude: $47^{\circ} 14$ Oeste e altitude: $220 \mathrm{~m}$ ). A semeadura nos dois locais ocorreu em 5 de novembro de 2018 e 15 de janeiro de 2019.

\section{Análise de solo e dados climáticos}

Nos locais de realização dos ensaios, foi realizada análise de solo a uma profundidade de $20 \mathrm{~cm}$, que apresentou os resultados, conforme Tabela 1.

Tabela 1. Resultado de análise de solo em Paraíso do Tocantins e Palmas

\begin{tabular}{llcc}
\hline Característica & \multicolumn{1}{c}{ Unidade } & $\begin{array}{c}\text { Paraíso } \\
\text { do } \\
\text { Tocantins }\end{array}$ & $\begin{array}{c}\text { Palm } \\
\text { as }\end{array}$ \\
\hline $\mathrm{pH}$ & $\mathrm{Cacl} 2$ & 06,1 & 05,9 \\
$\mathrm{P}$ & $\mathrm{mg} / \mathrm{dm}^{-3}$ & 14,1 & 06,8 \\
$\mathrm{~K}$ & $\mathrm{mg} / \mathrm{dm}^{-3}$ & 54,2 & 39,0 \\
$\mathrm{Ca}$ & $\mathrm{cmolc}_{\mathrm{dm}^{-3}}$ & 03,6 & 01,2 \\
$\mathrm{Mg}$ & $\mathrm{cmolc} / \mathrm{dm}^{-3}$ & 00,8 & 00,5 \\
$\mathrm{MO}$ & $\%$ & 01,6 & 01,0 \\
Saturação de base & $\%$ & 76,4 & 54,0 \\
$\mathrm{CTC}$ & $\mathrm{cmolc} / \mathrm{dm}^{-3}$ & 05,94 & 03,4 \\
\hline
\end{tabular}

pH - Potencial hidrogeniônico; $\mathrm{P}$ - fósforo; $\mathrm{K}$ - Potássio; $\mathrm{Ca}$ - Cálcio; Mg - Magnésio; MO - Matéria Orgânica; CTC Capacidade de troca de cátions.

Os dados climáticos foram obtidos da estação meteorológica localizada no Instituto Federal de Educação, Ciência e Tecnologia do Tocantins, Campus Paraíso do Tocantins, e da estação meteorológica do INMET, Palmas, Tocantins. Os dados se referem a temperatura média e precipitação, conforme as Figuras 1 e 2 .

\section{Delineamento experimental e condução dos ensaios}

$\mathrm{O}$ delineamento experimental utilizado, em cada ensaio, foi de blocos ao acaso, com três repetições e doze tratamentos. Os tratamentos constaram de 12 cultivares adquiridas no comércio local da região do estudo, sendo seis não transgênicas e seis transgênicas.

As cultivares não transgênicas foram codificados de 1 a 6 , sendo: 1CHD (Não transgênica Híbrido duplo), 2CV (Não transgênica Variedade), 3CV (Não transgênica Variedade), 4CV (Não transgênica Variedade), 5CHT (Não transgênica Híbrido Triplo), 6CHD (Não transgênica Híbrido Duplo). 
Figura 1. Precipitação pluvial e temperatura máxima diária para o período de novembro de 2018 a maio de 2019 para município de Paraíso do Tocantins

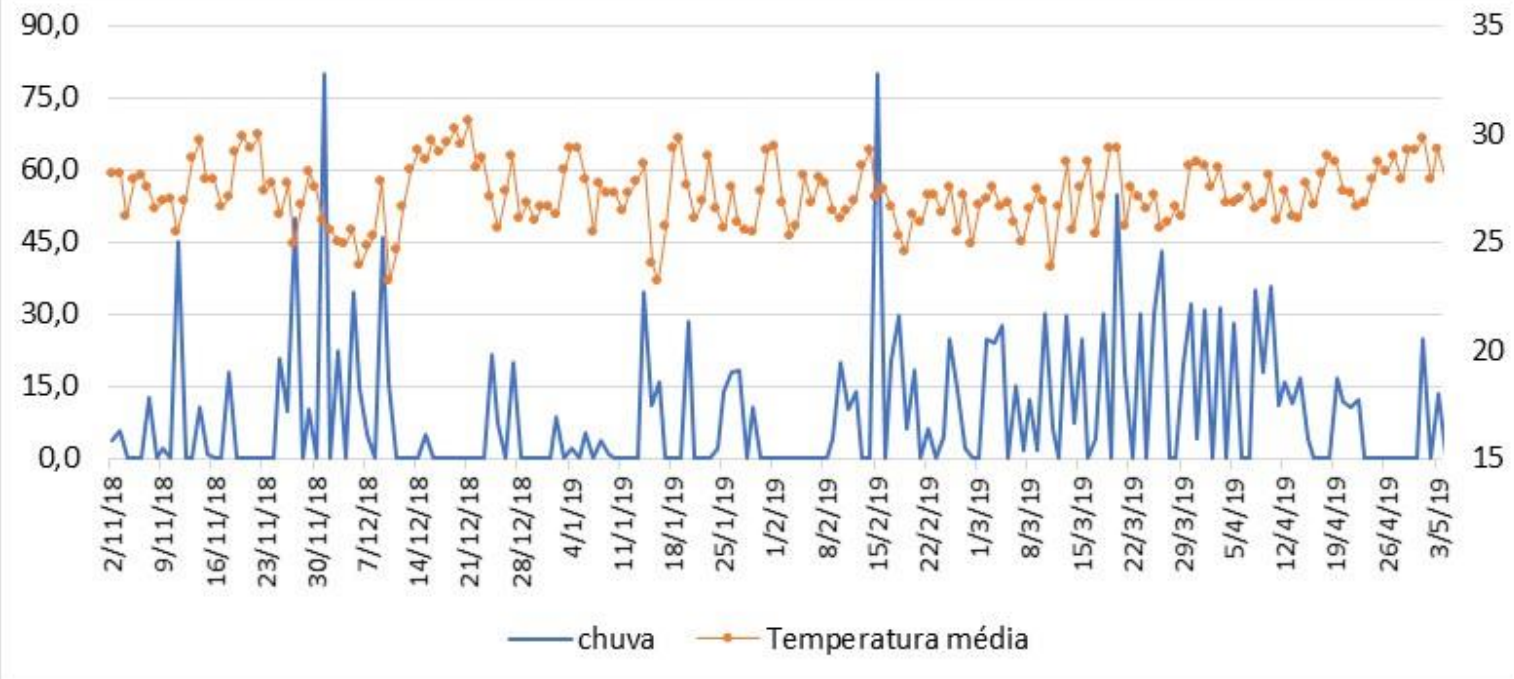

Fonte: Estação meteorológica do Instituto Federal de Educação, Ciência e Tecnologia do Tocantins, Campus Paraíso do Tocantins

Figura 2. Precipitação pluvial e temperatura máxima diária para o período de novembro de 2018 a maio de 2019 para município de Palmas.

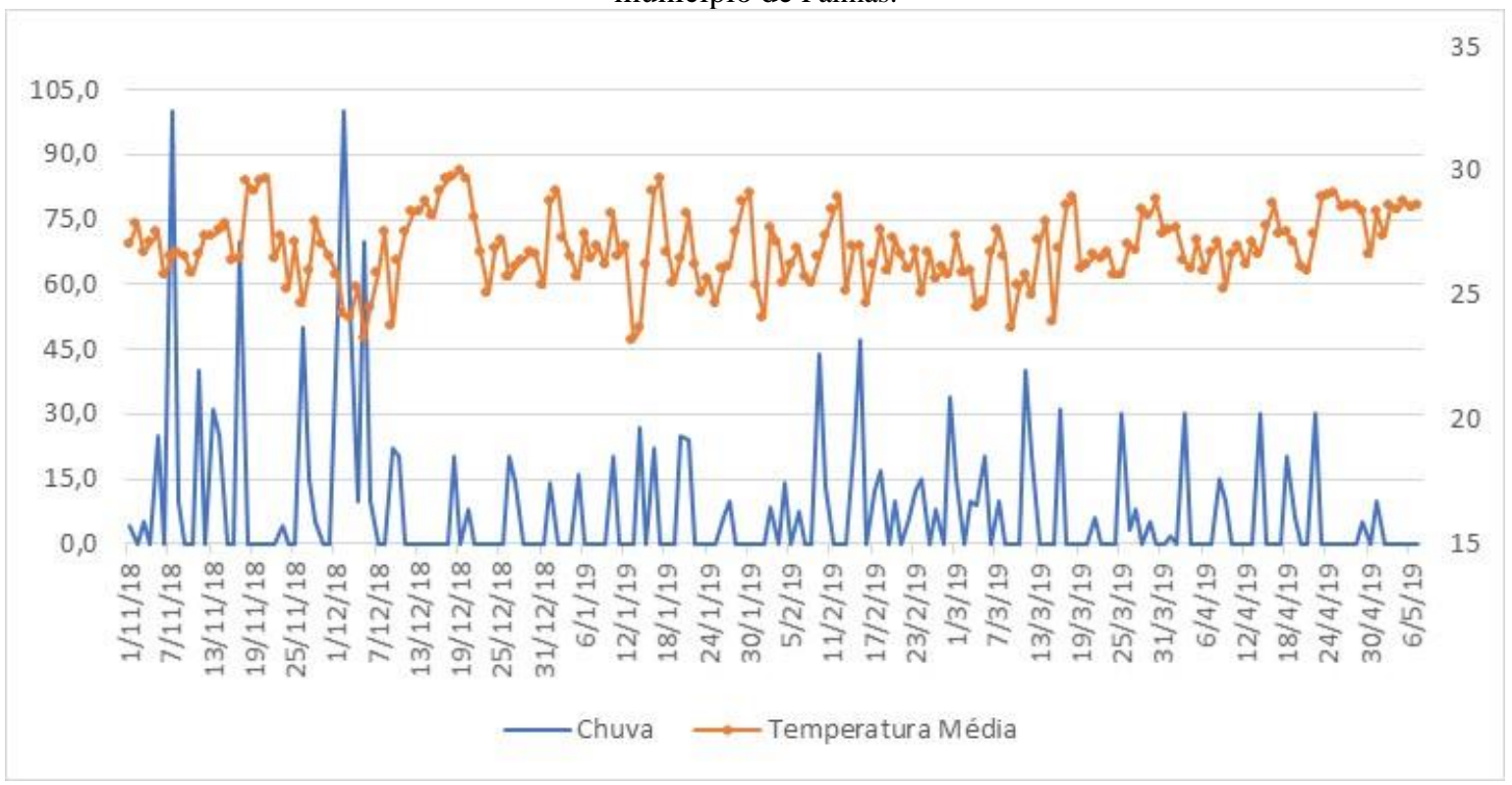

Fonte: Estação meteorológica do INMET, Palmas, Tocantins.

As cultivares transgênicas foram codificados de 7 a 12 sendo: 7THT (Transgênica Híbrido Triplo), 8THT (Transgênica Híbrido Triplo), 9THS (Transgênica Híbrido Simples), 10THS (Transgênica Híbrido Simples), 11THS (Transgênica Híbrido Simples), 12THS (Transgênica Híbrido Simples).
A parcela experimental foi composta por quatro linhas de $5 \mathrm{~m}$ de comprimento, espaçadas por 0,80 m. Na colheita, foram utilizadas as duas linhas centrais, descartando-se 0,50 m da extremidade de cada linha. 
Foi realizado o preparo do solo que consistiu das operações de gradagem e sulcamento. Com base nos resultados da análise de solo, foi realizada manualmente uma adubação de $400 \mathrm{~kg}$ de 4-14-8 por $\mathrm{ha}^{-1}$, no fundo do sulco de semeadura e, em cobertura, quando a planta apresentava entre 4 e 6 folhas estendidas, aplicando 50, 100 e $150 \mathrm{~kg}$ de $\mathrm{N}$ (Nitrogênio) por ha ${ }^{-1}$, utilizando como fonte o sulfato de amônio.

A semeadura foi realizada manualmente, distribuindo-se as sementes no sulco, em uma quantidade $20 \%$ superior à população recomendada, que foi de 50 mil plantas por ha ${ }^{-1}$. Aos 10 dias após a semeadura, foi realizado o desbaste das plantas, deixando o número de plantas por metro linear desejado. Os tratos culturais foram realizados conforme a necessidade e recomendações técnicas da cultura.

\section{Coleta e análise dos dados}

Com base na área útil da parcela, obtiveram-se a altura da planta (AP), o diâmetro do colmo (DC), o diâmetro da espiga com palha (DECP), o comprimento da espiga com palha (CECP), diâmetro da espiga sem palha (DESP) o peso da espiga sem palha (PESP), o número de fileiras por espiga (NFE), o número de grãos por fileira (NGF), a altura da espiga (AE), o peso hectolitro $(\mathrm{PH})$ e o peso de grãos (PG). Os descritores das características foram adaptados e utilizados conforme (TEIXEIRA e COSTA, 2010).

Após a obtenção dos dados, foi realizada a análise de variância para cada nível de adubação nitrogenada em cobertura $(50,100$ e $150 \mathrm{~kg}$ de $\mathrm{N}$ por ha $^{-1}$ ) e uma análise conjunta dos ensaios (envolvendo todas as doses de nitrogênio em cobertura). Com os resultados de cada análise de variância, foram obtidas as medidas de dissimilaridade, utilizando a distância generalizada de Mahalanobis e, posteriormente, foi aplicado o método de otimização de agrupamento de Tocher, proposto por Rao 1952. Para a análise conjunta, foi utilizado, ainda, o método hierárquico da distância média (UPGMA). Para quantificar a contribuição relativa das características, foi utilizado o critério de Singh 1981.

As análises estatísticas foram realizadas utilizando-se o programa Computacional Genes, versão 2007.

\section{RESULTADOS E DISCUSSÃO}

As estimativas da dissimilaridade entre os 12 cultivares de milho, transgênicas e não transgênicas, para as adubações de 50,100, $150 \mathrm{~kg}$ de $\mathrm{N}_{\text {por ha }}{ }^{-1} \mathrm{e}$ da análise conjunta, são apresentadas na Tabela 2.

Para a análise conjunta, a maior distância ocorreu entre uma cultivar não transgênica (2CV) e uma transgênica híbrida simples (11THS) $(46,3)$, seguida da distância entre duas transgênicas (8THT e 11THS) $(45,1)$.

Para a dose de $100 \mathrm{~kg}$ de $\mathrm{N}$ por ha ${ }^{-1}$, a maior distância, e para as doses de 50 e $150 \mathrm{~kg}$ de $\mathrm{N}_{\text {por ha }}{ }^{-1}$, segunda maior distância, foram estabelecidas pela combinação entre transgênica x transgênica, indicando diversidade genética entre as cultivares da mesma tecnologia.

As amplitudes dos valores das estimativas de dissimilaridade de Mahalanobis observadas, entre as maiores distâncias, sugerem variabilidade genética entre as cultivares de ambas tecnologias ou não, possibilitando o uso das mesmas como progenitores contrastantes para extração de linhagens endogâmicas ou diretamente no local do cultivo, evitando a erosão genética (SIMON et al., 2012).

Em todas as adubações e na análise conjunta, a combinação entre uma transgênica (7THT) e uma não 
transgênica (5CHT) apresentou sempre a menor distância, sendo ambos híbridos triplos. A segunda menor distância foi, novamente, estabelecida entre cultivares transgênicas e não transgênicas, em duas adubações e análise conjunta. Oliboni et al. (2012) afirmam que a divergência genética está relacionada ao grau de distância entre as populações no conjunto de caracteres genéticos que diferem entre as populações, o que aponta neste estudo, para a aproximação entre as tecnologias.

Tabela 2. Estimativa de dissimilaridade entre 12 cultivares de milho, transgênicas e não transgênica, em relação às

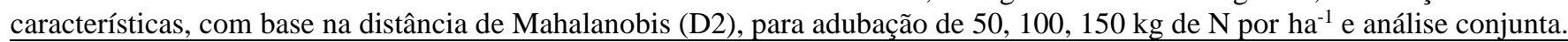

\begin{tabular}{|c|c|c|c|c|c|c|c|c|}
\hline \multirow[t]{2}{*}{ Cultivar } & \multicolumn{2}{|c|}{$50 \mathrm{~kg}$ de $\mathrm{N}$ por ha ${ }^{-1}$} & \multicolumn{2}{|c|}{$100 \mathrm{~kg}$ de $\mathrm{N}$ por ha ${ }^{-1}$} & \multicolumn{2}{|c|}{$150 \mathrm{~kg}$ de $\mathrm{N}$ por ha ${ }^{-1}$} & \multicolumn{2}{|c|}{ Conjunta } \\
\hline & Maior & Menor & Maior & Menor & Maior & Menor & Maior & Menor \\
\hline 1CHD & $42(2)$ & $7,7(5)$ & $28,8(2)$ & $4,7(5)$ & $28,4(2)$ & $5,4(7)$ & $23,8(2)$ & $3,7(5)$ \\
\hline $2 \mathrm{CV}$ & 46,3 (11) & $8,9(4)$ & $28,8(1)$ & $4,2(9)$ & $35,2(11)$ & $11,5(9)$ & $27,6(11)$ & $8,1(9)$ \\
\hline $3 \mathrm{CV}$ & $27,5(11)$ & $7,7(7)$ & $22,1(2)$ & $3,5(7)$ & $26,0(11)$ & $6,6(7)$ & $17,3(11)$ & $3,9(7)$ \\
\hline $4 \mathrm{CV}$ & $32,3(1)$ & $8,9(2)$ & $23,5(8)$ & $7,1(10)$ & $29,3(11)$ & $8,6(10)$ & $21,5(8)$ & $6,2(10)$ \\
\hline $5 \mathrm{CHT}$ & $30,2(8)$ & $3,8(7)$ & $2,14(2)$ & $2,1(7)$ & $25,8(8)$ & $3,1(7)$ & $20,3(8)$ & $1,2(7)$ \\
\hline 6CHD & $23,2(4)$ & $7,0(7)$ & $24,9(2)$ & $6,4(3)$ & $25,3(10)$ & $11,5(8)$ & $18,8(4)$ & $5,8(12)$ \\
\hline 7THT & $30,0(2)$ & $3,8(5)$ & $26,9(2)$ & $2,1(5)$ & $25,4(2)$ & $3,1(5)$ & $20,8(2)$ & $1,2(5)$ \\
\hline 8THT & $45,1(11)$ & $9,7(3)$ & $29,5(12)$ & $8,8(6)$ & $32,1(11)$ & $11,4(6)$ & $28,4(11)$ & $7,8(6)$ \\
\hline 9THS & $29,6(8)$ & $13,6(6)$ & $24,6(8)$ & $4,2(2)$ & $23,2(4)$ & $10,0(10)$ & $17,4(8)$ & $8,1(2)$ \\
\hline 10THS & $28,1(8)$ & $10,3(4)$ & $25,6(8)$ & $7,1(4)$ & $25,3(6)$ & $8,4(1)$ & $21,7(8)$ & $6,2(4)$ \\
\hline 11THS & 46,3 (2) & $7,4(12)$ & $25,8(8)$ & $7,9(5)$ & $35,2(2)$ & $9,2(11)$ & $28,4(8)$ & $5,5(12)$ \\
\hline $12 \mathrm{THS}$ & $30,0(8)$ & $6,8(7)$ & $29,5(8)$ & $9,3(5)$ & $26,7(4)$ & $9,2(11)$ & $22,9(8)$ & $5,5(11)$ \\
\hline
\end{tabular}

Fonte: dados da pesquisa

*Números fora do parêntesis: medidas de dissimilaridade

**Números dentro do parêntesis: genótipos

***1CHD (Não transgênica Híbrido duplo), 2CV (Não transgênica Variedade), 3CV (Não transgênica Variedade). 4CV (Não transgênica Variedade), 5CHT (Não transgênica Híbrido Triplo), 6CHD (Não transgênica Híbrido Duplo), 7THT (Transgênica Híbrido Triplo), 8THT (Transgênica Híbrido Triplo), 9THS (Transgênica Híbrido Simples), 10THS (Transgênica Híbrido Simples), 11THS (Transgênica Híbrido Simples), 12THS (Transgênica Híbrido Simples)

O agrupamento das cultivares, pelo método de

Tocher, envolvendo todas as doses de $\mathrm{N}$ ao mesmo tempo (análise conjunta) e em cada uma das doses de $\mathrm{N}$ (análises de 50,100 e $150 \mathrm{~kg}$ de $\mathrm{N}$ por ha ${ }^{-1}$ ) está apresentado na Tabela 3. Com exceção da dose de 100 $\mathrm{kg}$ de $\mathrm{N}$ por ha ${ }^{-1}$, onde foram formados seis grupos, nas demais doses e na análise conjunta foram formados cinco grupos.

Em todas as análises realizadas $(50,100$ e 150 $\mathrm{kg}$ de $\mathrm{N}$ por ha ${ }^{-1}$ e na análise conjunta), as cultivares 5CHT, 7THT, 1CHD, 3CV foram alocadas no mesmo grupo (Grupo 1), que foi o grupo constituído por um maior número de cultivares. Ressalta-se que grupos constituídos por maior número de cultivares apresentam menores distâncias e quanto menor a distância entre indivíduos, maior a similaridade genética entre os mesmos (SANTOS et al., 2014). Por outro lado, segundo Dias et al. (2018), as cultivares reunidas em grupos distintos são indicativos de dissimilaridade, podendo ser consideradas como promissoras em cruzamentos artificiais (DIAS et al., 2018) 
Tabela 3. Agrupamento pelo método de Tocher, com base na dissimilaridade expressa pela distância generalizada de Mahalanobis de 12 genótipos de milho, para análise conjunta, 50, 100 e $150 \mathrm{~kg}$ de $\mathrm{N}_{\text {por ha }}^{-1}$

\begin{tabular}{|c|c|c|c|c|}
\hline Grupos & $\begin{array}{l}\text { Análise } \\
\text { conjunta }\end{array}$ & $\begin{array}{c}\text { Análise } \\
50 \mathrm{~kg} \text { de N por } \\
\mathrm{ha}^{-1}\end{array}$ & $\begin{array}{c}\text { Análise } \\
100 \mathrm{~kg} \text { de } \mathrm{N} \text { por ha }{ }^{-1}\end{array}$ & $\begin{array}{c}\text { Análise } \\
150 \mathrm{~kg} \text { de } \mathrm{N} \text { por } \mathrm{ha}^{-1}\end{array}$ \\
\hline 1 & $\begin{array}{c}\text { 5HT, 7THT, } \\
1 \mathrm{CHD}, 3 \mathrm{CV}\end{array}$ & $\begin{array}{c}\text { 5CHT, 7THT, } \\
1 \mathrm{CHD}, 6 \mathrm{CHD}, \\
3 \mathrm{CV}, 12 \mathrm{THS}\end{array}$ & $\begin{array}{c}\text { 5CHT, 7THT, } \\
1 \mathrm{CHD}, 3 \mathrm{CV}\end{array}$ & $\begin{array}{c}\text { 5CHT, 7THT, } \\
1 \mathrm{CHD}, 3 \mathrm{CV}\end{array}$ \\
\hline 2 & $11 \mathrm{THS}, 12 \mathrm{THS}$ & $\begin{array}{c}2 \mathrm{CV}, 4 \mathrm{CV} \\
10 \mathrm{THS}\end{array}$ & 2CV, 9THS & 4CV, 10THS \\
\hline 3 & $4 \mathrm{CV}, 10 \mathrm{THS}$ & 8THT & 4CV, 10THS & 11THS, 12THS \\
\hline 4 & 6CHD, 8THT & 9THS & 6CHD, 8THT & 2CV, 9THS \\
\hline 5 & 2CV, 9THS & $11 \mathrm{THS}$ & $11 \mathrm{THS}$ & 6CHD, 8THT \\
\hline 6 & & & 12THS & \\
\hline
\end{tabular}

Fonte: Dados da pesquisa.

De acordo com Cruz e Regazzi (2004), o estabelecimento de grupos com genótipos com homogeneidade dentro e heterogeneidade entre os grupos é o ponto de partida para uma avaliação mais detalhada, a fim de realizar seu aproveitamento nos programas de melhoramento.

De modo geral, houve similaridade quanto à composição dos grupos formados, em doses distintas de $\mathrm{N}$, revelando uma baixa influência das doses de $\mathrm{N}$ na diferenciação das cultivares não transgênicas e transgênicas. Esses resultados estão em discordância com aqueles obtidos por Sodré et al. (2018) que afirmaram que as doses de $\mathrm{N}$ podem resultar em respostas diferenciadas dos genótipos, em virtude de melhor absorção e aproveitamento deste elemento no desenvolvimento da planta, propiciando diferenças na composição dos grupos.

Ressalta-se que a formação de grupos com as tecnologias não transgênica e transgênica apareceu em 14 das 21 composições, o que indica uma possível aproximação entre as tecnologias. As cultivares 11THS e 12THS, ambas transgênicas e híbridos triplos, aparecem isoladamente ou associadas em um mesmo grupo. Segundo Vieira et al. (2009), grupos constituídos por apenas uma cultivar aponta na direção de que tais indivíduos sejam mais divergentes em relação aos demais e desta forma mais promissores na obtenção de novos materiais.

O método UPGMA, realizado para a análise conjunta (Figura 3), apresentou similaridade quanto ao número e composição dos grupos em relação ao método de Tocher (Tabela 3). Segundo Aquino et al. (2018) a avaliação da dissimilaridade sob diferentes metodologias fornece maior confiabilidade no estudo, uma vez que cada método é baseado em diferentes técnicas. Em ambos os métodos, a presença de cultivares transgênicas e não transgênicas no mesmo grupo revela similaridade entre as cultivares oriundas de tecnologias distintas.

A contribuição relativa das características, que é de extrema relevância em programas de melhoramento, é apresentada segundo critério de Singh 1981, na Tabela 4. Dotto et al. (2010) ressaltam que quantificar a influência de cada característica na divergência genética entre cultivares é importante no direcionamento dos programas de melhoramento e na obtenção de cultivares mais produtivas.

As características que mais contribuíram para a explicação da divergência entre as cultivares estudadas em todos os níveis de adubação e análise conjunta 
foram o (CECP), (NGF) e (NFE), resultado semelhante ao encontrado por Simon et al. (2012). O (NFE) apresentou amplitude reduzida de contribuição entre as adubações, resultado também encontrado por Pizolato Neto et al. (2016).

Figura 3. Agrupamento, para análise conjunta, de 12 cultivares de milho transgênica e não transgênica por meio do método UPGMA (corte a 62\%) a partir da distância de Mahalanobis (D2)

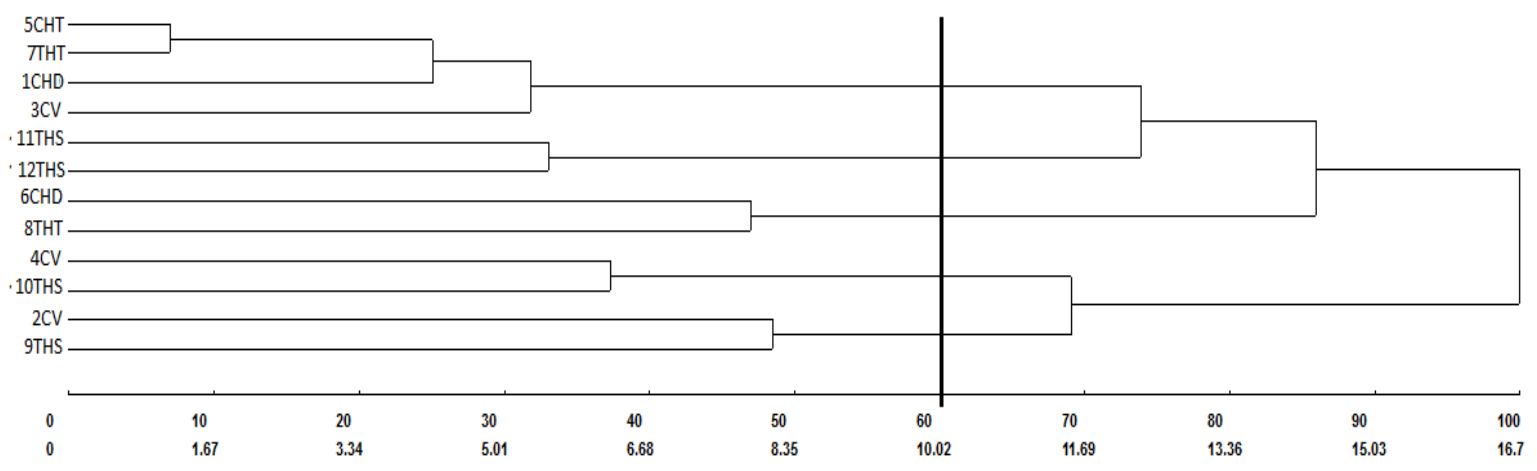

Fonte: Dados da pesquisa.

Tabela 4. Contribuição relativa, em porcentagem, das onze características para o processo de dissimilaridade genética dos genótipos de milho

\begin{tabular}{lcccc}
\hline Característica & $\begin{array}{c}\text { Análise } \\
\text { conjunta }\end{array}$ & $\begin{array}{c}50 \mathrm{~kg} \mathrm{de} \mathrm{N}_{\text {por ha }}{ }^{-1} \\
\text { por ha }\end{array}$ & $\begin{array}{c}100 \mathrm{~kg} \mathrm{de} \mathrm{N}^{-1} \\
150 \mathrm{~kg} \mathrm{de} \mathrm{N}^{-1} \\
\text { por ha }^{-1}\end{array}$ \\
\hline AP & 05,4 & 06,0 & 05,6 & 04,9 \\
DC & 02,0 & 03,4 & 00,0 & 06,2 \\
DECP & 05,4 & 04,8 & 05,2 & 07,3 \\
CECP & 18,5 & 12,4 & 25,7 & 12,1 \\
DESP & 09,3 & 09,3 & 06,2 & 11,7 \\
PESP & 02,4 & 03,2 & 05,8 & 04,4 \\
NFE & 17,0 & 15,6 & 14,5 & 11,3 \\
NGF & 20,6 & 20,6 & 09,3 & 22,6 \\
AE & 07,1 & 07,2 & 06,3 & 06,6 \\
PH & 08,6 & 05,5 & 14,8 & 06,9 \\
PG & 00,0 & 10,1 & 00,4 & 00,0 \\
\hline
\end{tabular}

Fonte: Dados da pesquisa.

*Altura da planta (AP), diâmetro do colmo (DC), diâmetro da espiga com palha (DECP), comprimento da espiga com palha (CECP), diâmetro da espiga sem palha (DESP), peso da espiga sem palha (PESP), número de fileiras por espiga (NFE), número de grãos por fileira (NGF), altura da espiga (AE), peso hectolitro $(\mathrm{PH})$, peso de grãos (PG).

Vale ressaltar que o NGF e o CECP são características correlacionadas (VILELA et al., 2012), sendo que o comprimento da espiga pode interferir na produtividade de grãos Silva et al. (2019). Neste sentido, para a formação de novos materiais, é interessante escolher cultivares que sejam divergentes entre si e com maior comprimento de espiga Pizolato Neto et al. (2016).

Com resultados análogos aos encontrados por Silva et al. (2019), a característica peso de grãos (PG) 
não figurou entre as características mais importantes na contribuição para a divergência entre as cultivares. Porém, por estar diretamente ligada à produtividade não deve ser negligenciada em trabalhos de melhoramento.

Em concordância com Sodré et al. (2018) o peso dos grãos (PG) teve maior contribuição em baixo $\mathrm{N}$ em cobertura, neste estudo $50 \mathrm{~kg}$ de $\mathrm{N}$ por ha- ${ }^{-1}$, indicando que quanto menor a adição de nitrogênio maior a contribuição da produtividade para a dissimilaridade, o que pode ser relacionado com a expressão gênica das cultivares que reagem de forma diferente em baixo nível de $\mathrm{N}$ adicionado ao solo em cobertura, provavelmente por ser uma característica quantitativa.

Pelo exposto acima, em virtude do grande número de características, que necessita de mão-deobra qualificada, tempo e suporte financeiro, a identificação das características que resultem em uma maior dissimilaridade entre cultivares, em programas de melhoramento, contribuem para a manutenção da diversidade genética da cultura, para a redução no tempo de construção de uma nova cultivar, na otimização no uso da mão-de-obra e na racionalização dos custos nos programas de melhoramento.

\section{CONCLUSÃO}

As características que mais contribuíram para a divergência genética foram o número de grãos por fileira e o comprimento de espiga com palha.

Houve baixa contribuição das doses de $\mathrm{N}$ para distinção das cultivares.

A dose de $100 \mathrm{~kg}$ de $\mathrm{N}$ por ha-1 foi a que resultou em um maior número de grupos, indicando que pode ser utilizada para estudos futuros para distinção de genótipos visando maximizar o uso de recursos.
Os grupos formados, em sua maioria, apresentaram cultivares transgênicas e não transgênicas, indicando similaridade entre cultivares de ambas tecnologias.

\section{AGRADECIMENTO}

Agradecemos a Coordenação de Aperfeiçoamento de Pessoal de Nível Superior CAPES/MEC, ao Instituto Federal de Educação, Ciência e Tecnologia do Tocantins.

Todos os autores declararam não haver qualquer potencial conflito de interesses referente a este artigo.

\section{REFERÊNCIAS}

AFFÉRRI, F. S.; DOTTO, M. A.; CARVALHO, E. V. DE; PELUZIO, J. M.; FARIA, L. A. de. Avaliação de genótipos de milho: adaptabilidade, estabilidade e estratificação ambiental. Revista Sítio Novo. v.4 n.2 p.81-92, 2020.

AQUINO, C. F.; SALOMÃO, L. C.; AZEVEDO, A. $M$. Genetic dissimilarity and relative importance of characteristics in banana cultivars through multivariate analysis. Revista Brasileira de Ciências Agrárias. v.12, n.4, p.399-404, 2017.

ARTUZO, F. D., FOGUESATTO, C. R., MACHADO, J. A. D., OLIVEIRA, L. DE; SOUZA, $\hat{A}$. R. L. de. O potencial produtivo brasileiro: uma análise histórica da produção de milho. Revista em Agronegócio e Meio Ambiente. v.12, n.2, p.515-540, 2019.

BURG, I. C. As estratégias de conservação on farm e as ameaças de erosão genética e do conhecimento associado às variedades crioulas de milho de agricultores familiares do município de novo horizonte - SC. Florianópolis, SC. Tese de doutorado. Universidade Federal de Santa Catarina. 2017.

CARVALHO, E.V.; AFFÉRRI, F.S.; PELUZIO, J.M.; ROTILI, E.A.; DOTTO, M.A.; FARIA, L.A. Parâmetros genéticos e associação de metodologias de EUN no milho sob diferentes doses de nitrogênio. Journal of Bioenergy and Food Science. v.3, n.1, 2016. 
COSTA, F. M. Diversidade genética e distribuição geográfica: uma abordagem para a conservação on Farm e ex situ e o uso sustentável dos recursos genéticos de milho do Oeste de Santa Catarina. Florianópolis, SC. Dissertação de Mestrado. Universidade Federal de Santa Catarina. 2013.

CRUZ, C. D.; REGAZZI, A. J. Modelos biométricos aplicados ao melhoramento genético. Viçosa: Imprensa Universitária. v.1. 20 ed. 480p. 2004.

DIAS, M. A. R.; MELO, A. V. DE; SANTOS, V. M. DOS; SANTOS, D. P. DA S.; NUNES, H. V. Divergência genética entre progênies de milho na região centro-sul do estado do Tocantins. Revista Engenharia na Agricultura - REVENG. n.26. p.483-496, 2018.

DINIZ, R. P. Adaptabilidade e estabilidade de híbridos de milho transgênicos e respectivos isogênicos não transgênicos. Lavras, MG. Dissertação de Mestrado. Universidade Federal de Lavras. 2011.

DOTTO, M. A.; AFFÉRRI, F. S.; PELUZIO, J. M.; MELO, A. V. DE.; CARVALHO, E. V. de. Divergência genética entre cultivares comerciais de milho em baixas altitudes no Tocantins, safra 2007/2008. Revista Ciência Agronômica. v.41, n.4, p.630-637, 2010.

FILHO, I. A. P.; BORGHI, E. 2018. Sementes de milho no Brasil: a dominância dos transgênicos. Embrapa Milho e Sorgo. Documentos. Sete Lagoas, MG.

INMET - Instituto Nacional de Meteorologia. Tempo. $2021 . \quad$ Disponível em: https://tempo.inmet.gov.br/TabelaEstacoes/A001. Acesso em: 08/05/2019.

NARDINO, M.; BARETTA, D.; CARVALHO, I. R.; FOLLMANN, D. N.; FERRARI, M.; PELEGRIN, A. J. DE; SZARESKI, V. J.; KONFLANZ, V. A.; SOUZA, V. Q. de. Divergência genética entre genótipos de milho (Zea mays L.) em ambientes distintos. Revista de Ciências Agrárias. n.40, p.164174. 2017.

OLIBONI, R.; FARIA, M. V.; NEUMANN, M.; BATTTISTELLI, G. M.; TEGONI, R. G.; RESENDE, J. T. V. Genetic divergence among maize hybrids and correlations with heterosis and combining ability. Acta Scientiarum. v.34, n.1, p.37-44, 2012.
PIZOLATO NETO, A., CAMARGOS, A.E.V., VALERIANO, T.B., SGOBI, M.A., SANTANA, M.J. Doses de nitrogênio para cultivares de milho irrigado. Nucleus. n.13, v.1, p.87-96, 2016.

RAMOS, L. N.; SOUZA, N. O. S.; VILELA, M. S. Parâmetros agronômicos e características morfoagronômicas de híbridos de milho geneticamente modificados comparados a híbridos de milho convencionais. Bioscience Journal. n.36, v.4, p.1156-1166, 2020.

SANTOS, W. F. DOS.; PELUZIO, J. M.; AFFÉRRI, F. S.; SODRÉ, L. F.; SANTOS, D. S. DOS; FARIAS, T. C. M. Variabilidade genética e eficiência de uso do nitrogênio em populações de milho para teor de óleo. Revista Ciências Agrárias. v.57, n.3, p.312-317, 2014.

SANTOS, W. F.; AFFÉRRI, F. S.; PELÚZIO, J. M.; SODRÉ, L. F.; ROTILI, E. A.; CERQUEIRA, F. B.; FERREIRA, T. P. S. Diversidade genética em milho sob estresse abiótico no Estado do Tocantins. Journal of Bioenergy and Food Science. n.5, v.2, p.44-53, 2018.

SILVA, K. C. L.; SANTOS, W. F.; AFFÉRRI, F. S.; PELUZIO, J. M.; SODRÉ, L. F. Diversidade genética em genótipos de milho de plantio tardio sob diferentes níveis de nitrogênio no Tocantins. Revista de Agricultura Neotropical. v.6, n.3, p.92-100, 2019.

SIMON, G. A.; KAMADA, T.; MOITEIRO, M. Divergência genética em milho de primeira e segunda safra. Semina: CiênciasAgrárias. v.33, n.2, p.449458, 2012.

SODRÉ, L. F.; SANTOS, W. F. DOS; ASCÊNCIO, S. D.; PELUZIO, J. M.; SILVA, R. M. DA; REINA, E. Divergência genética em milho para baixo e alto nitrogênio visando à produção de óleo e proteína. Pesquisa Agropecuária Pernambucana. v.22, n.1, p.1-7, 2018.

SODRÉ, L. F.; ASCÊNCIO, S. D.; PELUZIO, J. M.; AFFÉRRI, F. S.; SANTOS, W. F. DOS; CARVALHO, E. V. de. Cultivo para alto e baixo nitrogênio em genótipos de milho no Tocantins visando a produção de óleo. Revista de Agricultura. v.91, n.2, p.174-183, 2016.

TEIXEIRA, F. F.; COSTA, F. M. Caracterização de recursos genéticos de milho. Embrapa Milho e Sorgo. Documentos. Sete Lagoas, MG. 2010. 
ULTCHAK, A. A. DE M. S. Organismos geneticamente modificados: a legalização no brasil e o desenvolvimento sustentável. Interthesis. v.15, n.2, p.125-142, 2018.

VIEIRA, E.; FIALHO, J.; SILVA, M.; FUKUDA, W.M.G..; FALEIRO, F. Variabilidade genética do banco de germoplasma de mandioca da Embrapa cerrados acessada por meio de descritores morfológicos. Científica. v.36, n.1, p.56-67, 2009.

VILELA, R.G.; ARF, O.; KAPPES C.; KANEKO F. H.; GITTI D. DE C.; FERREIRA J. P. Desempenho agronômico de híbridos de milho, em função da aplicação foliar de fungicidas. Bioscience Journal. n.28, p.25-33, 2012. 